\title{
Development of the Web Users Self-Efficacy Scale (WUSE)
}

\section{Peter Eachus and Simon Cassidy Directorate of Psychology, University of Salford, Salford, UK}

\author{
p.eachus@salford.ac.uk s.cassidy@salford.ac.uk
}

\begin{abstract}
The aim of this research was to develop a scale that could evaluate an individuals confidence in using the Internet. Web-based resources are becoming increasingly important within higher education and it is therefore vital that students and staff feel confident and competent in the access, provision, and utilisation of these resources. The scale developed here represents an extension of previous research (Cassidy \& Eachus, 2002) that developed a measure of self-efficacy in the context of computer use. An iterative approach was used in the development of the Web User SelfEfficacy scale (WUSE) and the participants were recruited from the student body of a large University in the North West of the United Kingdom, and globally via a web site set up for this purpose. Initial findings suggest that the scale has acceptable standards of reliability and validity though work is continuing to refine the scale and improve the psychometric properties of the tool.
\end{abstract}

Keywords: Psychology, self-efficacy, teaching and learning

\section{Introduction}

In their exploration of factors affecting the success of online learning, Blocher, Sujo de Momtes, Willis \& Tucker (2002) considered whether online learners need specific skills and strategies to be successful. They examined factors including cognitive and metacognitive learning strategies and motivation and found that the online programme included in their study tended to attract students who were young and who were confident in their technology skills. Cassidy and Eachus (2002) have also identified confidence, or self-efficacy, as a pertinent factor in the context of computer use, with higher levels of computer user self-efficacy associated with greater self-rated computer competency and experience. Computer user self-efficacy relates specifically to an individual's judgement of their capabilities to use computers and is derived from Bandura's (1986) social cognitive theory in which he defines the general construct of self-efficacy as "peoples judgements of their capabilities to organize and execute courses of action required to attain designated types of performances. It is concerned not with the skills one has but with the judgements of what one can do with whatever skills one posses" (p.391). Simplified, self-efficacy represents

Material published as part of this publication, either on-line or in print, is copyrighted by the Informing Science Institute. Permission to make digital or paper copy of part or all of these works for personal or classroom use is granted without fee provided that the copies are not made or distributed for profit or commercial advantage AND that copies 1) bear this notice in full and 2) give the full citation on the first page. It is permissible to abstract these works so long as credit is given. To copy in all other cases or to republish or to post on a server or to redistribute to lists requires specific permission and payment of a fee. Contact Publisher@InformingScience.org to request redistribution permission. an individual's beliefs regarding their perceived capability to successfully complete a particular behaviour or task. The impact of positive and negative self-efficacy beliefs has been demonstrated in a range of contexts including academic achievement (; Cassidy \& Eachus, 2000; Eachus, 1993; Eachus \& Cassidy, 1997), health behaviour (Bandura, 1986; Schwarzer, 1992), stock 
market investment (Eachus, 1994) as well as more recently computer use (Cassidy \& Eachus, 2002).

Within the context of computer use, positive self-efficacy has been shown to be related to willingness to choose and participate in computer-based activities, expectations of success, perseverance when faced with difficulties and computer-based performance (Holcomb, Brown, Kulikowich \& Zheng, 2003). The effects of both gender and experience with computers have also been reported, with males and experienced computer users showing higher levels of computer user self-efficacy (Cassidy \& Eachus, 2002).

According to Bandura (1986), self-efficacy beliefs develop is response to four sources of information: previous experience (success and failure), vicarious experience; (observing others successes and failures); verbal persuasion (from peers, colleagues, relatives); and affective state (emotional arousal, e.g. anxiety). Because self-efficacy is based on self-perceptions regarding particular behaviours, the construct is considered to be situation specific or domain sensitive (Cassidy \& Eachus, 2002). To illustrate domain sensitivity Cassidy \& Eachus (2002) provide the example of an individual who may exhibit high levels of self-efficacy (indicating a high level of confidence) within one domain, for example sport, whilst simultaneously exhibiting low levels of self-efficacy within another domain such as academic ability. Bandura (1986) suggests that the perception that one has the capabilities to perform a task will increase the likelihood that the task will be completed successfully.

It is within the specific context of information and communication technologies and e-learning that the current paper examines self-efficacy beliefs, with specific reference to Internet or webbased resources. We are amidst a revolution involving virtual learning environments and identifying, measuring and manipulating any factor that might impede our access to, utilisation of, or success with virtual learning should be a principal concern of educational research and pedagogical practice.

There are many reasons or factors that make both access to, and utilisation of the Internet both desirable and necessary. Its ubiquitous nature has deemed access to and familiarity with the Internet an assumption of the modern age; not using the net may even be, as suggested by Wolfinbarger, Gilly \& Schau (2005), socially undesirable. However, although the human computer interface is becoming increasingly intuitive, for inexperienced users there are still formidable problems. The Internet has the potential to impact on many facets of our daily lives, but for many people the ability to exert that power is limited by an inability to control that potential. This inability may be real - in that the individual genuinely may not have the necessary skills or abilities - or it may simply be a belief which results in incapacity and poor motivation, as in the case of self-efficacy expectations (Cassidy \& Eachus, 2002). In their study examining Internet usage in older individuals, Wolfinbarger et al. (2005) have already demonstrated the effect of self-efficacy beliefs in determining propensity and intensity of Internet use, with positive beliefs associated with earlier adoption of and increased use of the Internet.

The nature of self-efficacy as an ego-centric construct demands that it be measured directly, rather than indirectly and for this reason self-efficacy is usually measured using self-report scales (Cassidy \& Eachus, 2002). Over the past decade a number of scales have been developed to measure various aspects of Internet self-efficacy. The early measures tended to focus on a few specific types of Internet behaviour, for example creating bookmarks or entering the address of a web page correctly (Nahl, 1996). Similarly Ren (1999) reports on a self-efficacy scale designed to evaluate searches for government information. A more general measure of Internet self-efficacy was developed by Eastin and LaRose (2000) and although the psychometric properties of this scale were adequate, the domain of behaviours examined was very limited and the scale itself only contained 8 items. 
The purpose of the research described here is to extend the work on Internet self-efficacy by developing a scale that will have broad utility. If students, and others who choose to learn online, are to gain maximum benefit from the experience it is important that tutors know something of their perceived capabilities before they embark on this form of learning. In this way it will be possible for tutors to identify students who could benefit from additional support before they face the frustrations of trying to tackle course material via a medium for which they are not best prepared.

\section{Method}

The construct of web user self-efficacy was sampled using items suggested by Nahl (1996), Ren (1999) and Eastin and LaRose (2000). In addition it was felt important that the items reflect four domains of Internet self-efficacy i.e. Information Retrieval, Information Provision, Communication, and Internet Technology. It was suggested that these four domains would cover aspects of Internet self-efficacy from the simplest retrieval of a web page up to the more complex issues associated with the design and construction of whole web sites. Examples of items from the four domains are shown in Table 1 . The first item is worded positively and the second negatively in each case:

\section{Table 1: Examples of items from the four domains}

Information Retrieval:

I rarely have problems finding what I am looking for on the Internet I sometimes find using search engines like Google and Yahoo can be difficult

Information Provision:

I wouldn't have any problems creating a simple web page.

Using ftp to upload web pages to a server is quite complicated.

Communication

I find using email easy.

I much prefer using letters or the telephone to communicate with people rather than the Internet.

Internet Technology

I can usually sort out any Internet access problems I may have. I am not really sure what a modem does.

From the items generated a 40-item scale was constructed where respondents were required to indicate their level of agreement/disagreement to each statement along a 5-point Likert scale. Affirmation bias was controlled for by wording half of the statements in a negative manner so that a disagree response was needed to add positively to the composite self-efficacy score. Hence a high score would indicate high self-efficacy on each of the four domains, which in turn could be totalled to provide an overall Web Users Self-Efficacy (WUSE) score.

In addition to the main scale items, data was also collected on age, gender, Internet expertise (novice, intermediate or advances), and Internet education (i.e. how the user had learned to access the Internet). This data was used for validation purposes. 


\section{Sampling}

Since the study was concerned with web user self-efficacy it seemed relevant to sample from the population of web users. This does create certain sampling problems, for example nothing is known about non-responders, and those who do respond obviously require a certain degree of Internet expertise and therefore completely naive respondents will probably be missed. However with the judicious use of target populations, in this case Usenet news groups, it is suggested that many of these problems were minimised. The aim was to achieve a sample with a wide age range, adequate gender representation, and a good cross section of experience. In order to achieve this a number of specific newsgroups were targeted, designed to give a balance between people who were likely to be very active on the Internet and those who were less so. The final newsgroups selected were: comp.internet.net-happenings; uk.people.silversurfers; misc.consumers; soc.senior.issues; alt.computer; talk.politics.misc; misc.rural; alt.internet; misc.activism.progressive; alt.education; and humanities.classics.

In addition to the web-based sample, students from a large University in the North West of the United Kingdom were also recruited for the study. These students were not studying computer or Internet based courses and therefore their experience with these technologies would be expected to be somewhat less than the sample recruited via the web. It was felt that this would make the whole sample more balanced and therefore more representative of web users.

\section{Procedure}

The 40 item scale was converted into an html form and uploaded onto the University server. To recruit participants for this study a message was posted on the selected newsgroup explaining the nature of the research and inviting people to participate. The URL of the web site was also provided allowing would be participants direct access.

On entering the web site and after reading the brief instructions and a statement assuring anonymity the participants were required to express the extent of their agreement with the items in the scale by clicking on one of five radio buttons ranging from Strongly Disagree through to Strongly Agree. After completing all 40 items the participant was presented with a "submit" button that on clicking sent the data to the University server. The server then responded with a "Thank You" screen before stripping the data of any identifying features and then emailing the data to the researchers.

For student participants a paper version of the scale was prepared and after explaining the purpose of the research the students were asked to complete the questionnaire by expressing their agreement/disagreement with the statements provided using a five point Likert scale.

\section{Results}

A total of 141 completed questionnaires were returned, 68 from the web based sample and 73 from the student participants. The mean age of the web group was 46 years with a range from 13 to 72 years (standard deviation 16.3). Of these, 52 were male, 15 female and one did not specify. For the student group the mean age was 21 with a range of 18-53 years (standard deviation 7.6), 13 male and 60 female. For the sample as a whole the mean age was 33 years with a range of 1372 (standard deviation 17.5) and the gender split was 65 males and 75 females. Preliminary analysis examined the data from the two samples separately and the findings are presented below. 


\section{Reliability}

Table 2 shows the means, standard deviations and alpha coefficients for the four domains and the WUSE scale as a whole. For each domain the minimum and maximum scores are 10 and 50 respectively. For the WUSE scale the minimum is 40 and the maximum 200. The reliability of each domain was measured using Cronbach's alpha.

Table 2. Web User Self-Efficacy Scores

\begin{tabular}{|l|ll|ll|ll|}
\hline \multirow{2}{*}{ Domain } & \multicolumn{2}{|c|}{ Mean } & \multicolumn{2}{c|}{$\begin{array}{c}\text { Standard } \\
\text { Deviation }\end{array}$} & \multicolumn{2}{c|}{ Alpha } \\
& Web & Students & \multicolumn{2}{c|}{ Web } & Students \\
& & & Web & Students & & \\
\hline Information Retrieval & 45.19 & $36.63 *$ & 4.90 & 7.59 & 0.778 & 0.852 \\
\hline Information Provision & 39.29 & $23.12 *$ & 9.84 & 8.94 & 0.909 & 0.883 \\
\hline Communications & 38.24 & $31.91 *$ & 5.70 & 7.09 & 0.617 & 0.755 \\
\hline Internet Technology & 41.12 & $28.25 *$ & 5.41 & 8.36 & 0.685 & 0.822 \\
\hline WUSE & 165.53 & $119.95 *$ & 20.34 & 28.17 & 0.907 & 0.943 \\
\hline
\end{tabular}

${ }^{*} p<0.001$

It can be seen from Table 2, using an alpha of 0.80 as a criterion (Howitt \& Cramer, 2005) that the domains of Information Retrieval, Information Provision and the WUSE scale as a whole all reach acceptable levels of reliability. In the case of Communications and Internet Technology only the students achieve Alpha's that meet this criterion.

Comparing the two sample groups across the five domains found significant differences in all cases (Information Retrieval, $\mathrm{t}=7.739$, $\mathrm{df}=134 \mathrm{p}<0.001$; Information Provision, $\mathrm{t}=10.075$, $\mathrm{df}$ $=135, \mathrm{p}<0.001$; Communications, $\mathrm{t}=5.489$, df = 128, $\mathrm{p}<0.001$; Internet Technology, $\mathrm{t}=$ 10.435, $\mathrm{df}=134, \mathrm{p}<0.001$; WUSE, $\mathrm{t}=9.956, \mathrm{df}=123, \mathrm{p}<0.001)$.

For the two sample groups combined, summary statistics are shown in Table 3.

Table 3. Web User Self-Efficacy Scores for combined group

\begin{tabular}{|l|c|c|c|}
\hline Domain & Mean & $\begin{array}{c}\text { Standard } \\
\text { Deviation }\end{array}$ & Alpha \\
\hline Information Retrieval & 40.59 & 7.70 & 0.880 \\
\hline Information Provision & 30.67 & 12.36 & 0.937 \\
\hline Communications & 34.69 & 7.22 & 0.747 \\
\hline Internet Technology & 34.23 & 9.59 & 0.876 \\
\hline WUSE & 138.92 & 33.76 & 0.960 \\
\hline
\end{tabular}

\section{Validity}

In order to assess the discriminant validity of the WUSE scale, participants had been asked to rate their level of expertise on a three point scale: Novice, Intermediate and Advanced. It was predicted that there would be significant differences in the WUSE scores obtained by these three groups. ANOVA was used to confirm this prediction $(\mathrm{F}=72.60, \mathrm{p}<0.001)$. It was also predicted 
that similar differences would be obtained for the four domains and this was also confirmed (Table 4).

Table 4. Mean Self-Efficacy Scores and Level of Expertise

\begin{tabular}{|c|c|c|c|c|}
\hline Domain & Novice & Intermediate & Advanced & F \\
\hline Information Retrieval & 27.72 & 38.40 & 46.45 & $59.84^{*}$ \\
\hline Information Provision & 15.63 & 25.47 & 41.88 & 80.41 * \\
\hline Communications & 25.81 & 33.22 & 38.75 & 24.48 * \\
\hline Internet Technology & 20.36 & 30.41 & 42.18 & 60.84 * \\
\hline WUSE & 89.54 & 127.51 & 169.40 & 72.60 * \\
\hline
\end{tabular}

${ }^{*} p<0.001$

Post hoc tests on the four domains and the WUSE scores all proved to be significant in the way predicted, i.e. the Advanced group achieved the highest scores, the Intermediate the next highest and the Novice group had the lowest scores.

Intuitively the four domains would appear to represent different levels of web user self-efficacy. It seems probable that most Internet users simply retrieve information or perhaps use it for communications, e.g. email. Only the more experienced and skilled user will be providing information in the form of web site design. It seems likely that these people will also be more knowledgeable as far as Internet technology is concerned. To examine this, a repeated measures anova was performed comparing the data from the four domains and this was found to be significant $(\mathrm{F}=86.14, \mathrm{p}<0.001)$. A paired sample t-test was used to compare each of the domains with the others. Multiple comparisons using a t-test in this way can be problematic and to correct for this the procedure suggested by Dancy and Reidy (2002) was followed. This suggests that the chosen significance level (0.05) should be divided by the number of comparisons (6) to give a corrected level of significance, in this case 0.008 . When the self-efficacy scores on the four domains are all compared with each other in this way, with the exception of Communications compared with Internet Technology, all the other comparisons proved to be statistically significant with $\mathrm{p}<$ 0.001 for each comparison.

Stereotypically, Internet users are usually perceived as young and male. In this study the gender split was almost equal with 65 males and 75 females. However it was also hypothesised that there would be significant gender differences obtained on the WUSE scores and the four domains with males would scoring more highly. This prediction was confirmed (Information Retrieval, $\mathrm{t}=$ 6.188, $\mathrm{df}=133$, $\mathrm{p}<0.001$; Information Provision, $\mathrm{t}=7.091$, $\mathrm{df}=134, \mathrm{p}<0.001$; Communications, $\mathrm{t}=3.646, \mathrm{df}=127, \mathrm{p}<0.001$; Internet Technology, $\mathrm{t}=8.147$, $\mathrm{df} 137, \mathrm{p}<0.001$, WUSE, $\mathrm{t}$ $=7.068, \mathrm{df}=122, \mathrm{p}<0.001)$.

Just why males should score more highly than females on all dimensions of the scale is perhaps revealed when gender differences in accessing the Internet is examined. In this study males report that they have been using the Internet regularly for significantly longer than females, 7.9 and 4.1 years respectively $(\mathrm{t}=5.923, \mathrm{df}=137, \mathrm{p}<0.001)$. Males also spend more hours per week on the Internet than do females, 24.1 and 10.8 hours respectively, $(\mathrm{t}=4.182, \mathrm{df}=135, \mathrm{p}<0.001)$.

If the Internet really is a plaything of the young then we would expect to find that younger people score more highly on the WUSE and its sub scales than would older people. To test this it was 
predicted that there would be a negative correlation between age and WUSE scores i.e. older people would exhibit lower levels of Internet self-efficacy when compared with young users. One difficulty in testing this hypothesis is that the Web sample is on average considerably older than the student sample, 33 and 21 years respectively. For this reason partial correlation coefficients were calculated controlling for the source of the data, i.e. web or student. The predicted relationships were tested using Spearman's rho and found to be supported. WUSE $(r=-0.253, p<0.005)$. Similar findings were confirmed for three of the four domains; Information Provision $(r=-0.205$, $\mathrm{p}<0.02)$, Communications $(\mathrm{r}=-0.358, \mathrm{p}<0.001)$ and Information Retrieval $(\mathrm{r}=-.196, \mathrm{p}<0.03)$. No significant correlation with age was obtained for Internet Technology $(r=-0.132$, ns).

Further validation of the WUSE scale was sought by asking participants where they were most likely to access the Internet, from home, at work, or both. It was hypothesised that those who access the Internet from home would probably use the Internet less and therefore would have the lowest self-efficacy scores, those who access the Internet from both home and work would score the highest, and those who mainly access it from work would fall somewhere in between. This hypothesis was tested using oneway analysis of variance and the results can be seen in Table 5 . This table shows the mean self-efficacy scores for each domain and the WUSE as a whole. All reach statistical significance in the direction predicted. Post hoc analysis revealed that for Information Retrieval and the WUSE as a whole the differences between the three access groups were statistically significant. However for the Information Provision and Internet Technology domains the difference between home and work access was not significant. Similarly for the Communications domain the difference between access from work and access from both home and work, also failed to reach significance. This data therefore can only be said to partly support the proposed hypothesis.

Table 5: Influence of Internet Access on Self-Efficacy

\begin{tabular}{|l|c|c|c|c|}
\hline \multicolumn{1}{|c|}{ Domain } & Home & Work & Both & $\begin{array}{c}\text { F } \\
\text { Significance }\end{array}$ \\
\hline Information Retrieval & 32.33 & 40.11 & 43.42 & 5.343 \\
& & & & 0.006 \\
\hline Information Provision & 23.33 & 29.41 & 35.71 & 4.965 \\
& & & & 0.008 \\
\hline Communications & 28.00 & 34.69 & 36.07 & 3.118 \\
& & & & 0.048 \\
\hline Internet Technology & 25.88 & 33.28 & 37.61 & 4.394 \\
& & & & 0.014 \\
\hline WUSE & 109.55 & 137.50 & 152.82 & 6.360 \\
& & & & 0.002 \\
\hline
\end{tabular}

In developing the WUSE scale it was suggested that Internet use could be divided into four domains, Information Retrieval, Information Provision, Communications, and Internet Technology. To test the proposition that these four domains are independent constructs the responses to the forty items of the scale were subject to factor analysis using principal component analysis and varimax rotation. The factor analysis produced seven factors with eigenvalues over one which accounted for $64 \%$ of the variance. The factor loadings did not allow any clear distinctions to be made in terms of the predicted domains. Indeed when the intercorrelations of the domain scores 
are examined, Table 6, it can be seen that there is considerable overlap between the four domains suggesting that Web User Self-Efficacy is best explained as a unitary construct rather than multidimensional.

Table 6: Domain Intercorrelations

\begin{tabular}{|c|c|c|c|c|}
\hline Domain & $\begin{array}{c}\text { Information } \\
\text { Retrieval }\end{array}$ & $\begin{array}{c}\text { Information } \\
\text { Provision }\end{array}$ & Communications & $\begin{array}{c}\text { Internet } \\
\text { Technology }\end{array}$ \\
\hline $\begin{array}{c}\text { Information } \\
\text { Retrieval }\end{array}$ & 1.00 & 0.791 & 0.713 & 0.868 \\
\hline $\begin{array}{c}\text { Information } \\
\text { Provision }\end{array}$ & & 1.00 & 0.650 & 0.850 \\
\hline Communications & & & 1.00 & 0.709 \\
\hline Internet Technology & & & & $\mathbf{1 . 0 0}$ \\
\hline
\end{tabular}

All the correlations were calculated using Spearman's rho (2-tailed) and are statistically significant $(\mathrm{p}<0.01)$.

\section{Discussion}

The principal aim of the study was to develop a psychometric instrument capable of measuring the self-efficacy construct in the context of Internet use. This aim relates to similar instrument development within the context of computer user self-efficacy (Cassidy \& Eachus, 2002). Given the centrality of electronic communication and resources in everyday functioning, professional competence, education and training, and the inhibitory effects of negative self-efficacy beliefs reported by Eachus \& Cassidy (1997) and facilitatory effects of positive self-efficacy beliefs (Holcomb et al. 2003), the development of an instrument to assess perceived capabilities around internet use was considered a worthwhile pursuit.

The Web User Self-Efficacy Scale (WUSE) was therefore developed on this basis and this first phase of development has been largely successful in demonstrating acceptable psychometric properties and utility of the instrument.

\section{Reliability}

Internal reliability of both the total WUSE scale and the composite sub-domains was assessed using Cronbach's Alpha. An alpha coefficient of 0.96 was reported for the total scale, while alphas for the four subscales ranged between 0.75 and 0.94 , which-according to developmental criteria suggested by Kline (1986) indicates acceptable levels of internal item consistency and reliability at both sub-scale and total scale levels. As the sample was derived from what could be considered two distinct populations, separate alpha coefficients were calculated for participants who completed the WUSE online and those who completed an off-line paper version. Results indicated similarly acceptable internal reliability for both groups on the total WUSE and subscales with the exception of Communications and Internet Technology subscales for the webbased group, where alpha levels were reported at marginally below the set criteria, i.e. Communications 0.62 and Internet Technology 0.69. Although further refinement of the scale is planned to address this issue, it is suggested that the tool is appropriate for both on-line and off-line completion. External (test-re-test) reliability was not assessed as this stage of development. 


\section{Validity}

Previous work (Cassidy \& Eachus, 2002) reports experience with computers as a significant factor in determining computer user self-efficacy, with increased experience leading to positive selfefficacy beliefs. The validity of the WUSE was demonstrated by significant differences in both total and subscale scores between groups reporting themselves as novice, intermediate and advanced Internet users. Advanced participants achieved higher WUSE (and subscale) scores than intermediate participants who, in turn, achieved higher WUSE (and subscale) scores than novice participants. This fits with earlier reports by Wolfinbarger et al. (2005) that self-efficacy is associated with intensity of Internet use.

According to the rationale that the prevailing function for most Internet users is information retrieval and communication, these two subscales should record higher levels of self-efficacy on the basis that participants will be more 'practised' in these domains. Although not all permutations of subscale comparisons proved significant, sufficient evidence was reported to support the proposition and thus further support the validity of the WUSE and its subscales.

In line with previous reports of gender differences in computer user self-efficacy (Cassidy \& Eachus, 2002), validity of the WUSE was examined according to the known groups method. The WUSE (and its subscales) successfully distinguished between groups of males and females, with males scoring significantly higher on total scale scores and all subscales. It is suggested that the gender difference reported here may be an artefact of experience and expertise as, males reported themselves as regular users for significantly longer than females.

In addition, some evidence was reported for an age dependent effect, with older participants having lower WUSE scores than younger participants, and for place of Internet access, with home only access group scoring lower than work only, and home plus work gaining the highest scores. Both of these effects were anticipated on the basis of the findings reported by Cassidy and Eachus (2002) and Wolfinbarger et al. (2005) and can be considered further evidence for the validity of the scale.

Although the authors remain confident of the content validity of the instrument, factor analysis did not produce a convincing four factor solution in accordance with those domains nominated: Information Retrieval; Information Provision; Communications; and Internet Technology. Instead a seven factor model accounting for $64 \%$ variance was reported. That factor loadings were not clearly indicative of source domains, and that inter-correlations between the originally proposed domains were high, means that it is not helpful to consider web-user self-efficacy in multidimensional terms. Instead, the construct should be treated as unidimensional, pending further investigation.

\section{Conclusion}

Although a programme of further development and refinement is planned, preliminary results do provide strong support for the utility of the existing 40-item WUSE scale. Like computer user self-efficacy, assessing web user self-efficacy will allow some insight into the implications and impact of positive and negative belief systems for individuals in many areas including both personal and professional functioning, and enable consideration to be given to interventions which will alleviate the effects of inhibitory beliefs systems such as low or negative web-user selfefficacy. Specific examples might include tutors or trainers who are thinking of using Internet based resources as either part or even the whole of a course, and who wish to evaluate web-user self-efficacy in their students as either a criterion for recruitment or to identify the need for further skill development. There is sufficient evidence within the self-efficacy literature to support the argument which suggests that negative web-user self-efficacy beliefs will inhibit successful 
internet use and thus limit utility of ICT in such areas as virtual learning. As further evidence is gathered-both practice-based and through research activity - the authors are optimistic that the WUSE will establish itself as robust, domain-specific tool for assessment of self-efficacy in the context of internet use.

\section{References}

Bandura, A. (1986). Social foundations of thought and action: A social cognitive theory. Englewood Cliffs, NJ: Prentice Hall.

Blocher, J. M.; Sujo de Momtes,L., Willis, E. M., \& Tucker, G. (2002). Online learning: Examining the successful student profile. The Journal of Interactive Online Learning, 1(2), 1-12.

Cassidy, S. \& Eachus, P. (2000). Learning style, academic belief systems, self-report student proficiency and academic achievement in higher education. Journal of Educational Psychology, 20(3), 307-322.

Cassidy, S \& Eachus, P. (2002). Developing the computer user self-efficacy (CUSE) scale: Investigating the relationship between computer self-efficacy, gender and experience with computers. Journal of Educational Computing Research, 26(2), 169-189, 2002.

Dancy, C. P., \& Reidy, J. (2002). Statistics without maths for psychology: Using SPSS for Windows. Pearson:Prentice Hall.

Eachus, P. (1993). Development of the health student self-efficacy scale. Perceptual and Motor Skills, 77, 670.

Eachus, P. (1994). Locus of control, self-efficacy and attributional style of investment professionals. Unpublished $\mathrm{PhD}$ Thesis. Manchester Metropolitan University.

Eachus, P. \& Cassidy, S (1997). Self-efficacy, locus of control and styles of learning as contributing factors in the academic performance of student health professionals. Proceedings of First Regional Congress of Psychology for Professionals in the Americas - Interfacing the Science and Practice of Psychology, July 27-August 2, 1997, Mexico City, Mexico.

Eastin, M.S. \& LaRose, R. (2000). Internet self-efficacy and the psychology of the digital divide. Journal of Computer-Mediated Communication, 6(1). Retrieved from http://www.asusc.org/jcmc/vol6/issue1/eastin.html

Howitt, D. \& Cramer, D. (2005). Introduction to statistics in psychology ( $3^{\text {rd }}$ ed.). Pearson: Prentice Hall.

Holcomb, L. B., Brown, S. W., Kulikowich, J. M. \& Zheng, D. (2003). Raising educational technology self-efficacy through assessment. American Psychological Association Conference, $30^{\text {th }}$ May $-2^{\text {nd }}$ June 2003, Altanta, USA. Retrieved online at: http://teachtech.education.uconn.edu/holcomb_asp.pdf

Kline, P. (1986). A handbook of test construction: Introduction to psychometric design. London: Methuen.

Nahl, D. (1996). Affective monitoring of Internet learners: Perceived self-efficacy and success. Journal of American Society for Information Sciences, 33, 200-209.

Ren, W. (1999). Self-efficacy and the search for government information. Reference \& User Service Quarterly, 38, 283-291.

Schwarzer, R. (1992). Self-efficacy: Thought control of action. London: Hemisphere.

Wolfinbarger, M., Gilly, M. C. \& Schau, H. J. (2005). Keeping up with the times: Innovation and usage of the Internet among later adopters. CRITO Consortium Project. Accessed online February 2006 from: www.crito.uci.edu/consortium 


\section{Biographies}

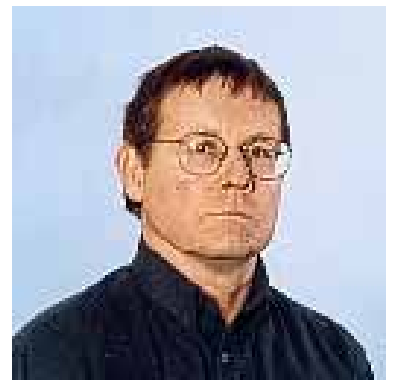

Peter Eachus is a Senior Lecturer in Psychology at the University of Salford. As well as his interests in the psychological aspects of Internet use, he also has research interests in robotics and the psychology of tourism. He has published extensively and has presented papers at conferences in North America, Spain, Italy, Belgium and the United Kingdom. Outside interests include running marathons and skydiving.

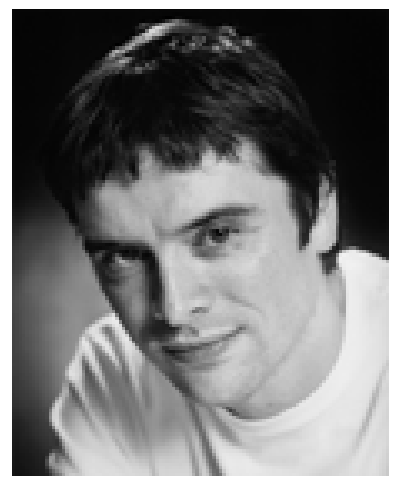

Simon Cassidy is a Chartered Psychologist and Senior Lecturer and Researcher based at the University of Salford, UK. Principle areas of teaching and research include in applied social psychology, health psychology, health promotion and educational psychology. He has an established national and international research profile which includes paper presentations in South America, Europe and the UK and publications in international journals such as Educational Psychology, Educational Computing Research and Perceptual and Motor Skills. 